\title{
PRONÚNCIA COMO CAUSA INTERRUPTIVA DA PRESCRIÇÃO E POSTERIOR DESCLASSIFICAÇÃO NO TRIBUNAL DO JÚRI
}

\author{
Thais Fernanda Silva Rogério, Antônio Roberto Sylla
}

Universidade do Oeste Paulista - UNOESTE, curso de Direito, Presidente Prudente, SP. E-mail: thais_fsr@hotmail.com

\section{RESUMO}

O presente estudo objetiva a demonstrar como permanecerá a situação da prescrição, após pronunciado o réu, nos casos de posterior desclassificação perante o conselho de sentença, no Tribunal do Júri, enfatizando-se se a prescrição será ou não interrompida, visando, principalmente, a uma maior contribuição com as atividades de pesquisa no Curso de Direito e a participação dos alunos, numa perspectiva científica. O artigo utilizou-se do método hipotético-dedutivo, baseando-se em pesquisas bibliográficas e jurisprudenciais, tendo a intenção de possibilitar a compreensão pertinente do estudo. Os resultados foram persuasivos, eis que foi possível observar os principais efeitos do instituto da prescrição. Conclui-se, no âmbito do Tribunal do Júri, referido instituto possui grande importância, construindo as bases do trabalho numa interpretação reflexiva e dialética.

Palavras-chave: Tribunal do Júri. Pronúncia. Prescrição. Interrupção. Desclassificação.

\section{PRONUNCIATION AS AN INTERRUPTIVE CAUSE OF THE PRESCRIPTION AND AFTER DECLASSIFICATION IN THE JURY COURT}

\begin{abstract}
The present study aims to demonstrate how the prescription situation will remain, after pronouncing the defendant, in cases of subsequent disqualification before the sentencing council, in the Court of the Jury, emphasizing whether or not the prescription will be interrupted, aiming mainly at $A$ greater contribution with the research activities in the Course of Law and the participation of the students, from a scientific perspective. The article used the hypotheticaldeductive method, based on bibliographical and jurisprudential research, with the intention of enabling the relevant understanding of the study. The results were persuasive, so it was possible to observe the main effects and importance of the prescription institute. It is concluded, in the scope of the Jury's Court, that institute has great importance, building the bases of the work in a reflexive and dialectical interpretation.
\end{abstract}

Keywords: Jury Court. Pronunciation. Prescription. Interruption. Disqualification.

\section{INTRODUÇÃO}

O presente trabalho abrange, inicialmente, o instituto da prescrição penal, destacando-se sua definição legal, qual seja, a perda do direito do Estado de punir, em decorrência do decurso de lapso temporal previsto na lei. No mais, no tópico seguinte, destacam-se as espécies de prescrição penal existente dentro do ordenamento jurídico pátrio, isto é, a prescrição da pretensão punitiva (PPP) e a prescrição da pretensão executória (PPE), demonstrando-se suas subespécies e regulamentação legal.

Ademais, o trabalho aborda, ainda, as causas interruptivas da prescrição, sendo este um dos pontos mais relevantes do presente tema, dando-se maior ênfase à sentença de pronúncia, 
sendo esta uma das possíveis decisões a serem proferidas pelo juiz togado, no rito do Tribunal do Júri, a qual tem o condão de interromper o prazo prescricional.

Seguindo-se esta ordem, já no tópico referente ao tema, serão abordadas as duas espécies de desclassificação dentro do rito do Tribunal do Júri, destacando-se quais delas interrompem a prescrição. Por fim, como objeto principal do trabalho, serão destacados os posicionamentos doutrinários e jurisprudenciais a respeito da subsistência ou não da sentença de pronúncia como causa interruptiva da prescrição, nos casos de posterior desclassificação do delito pelo conselho de sentença, no Tribunal do Júri.

Fixadas tais asserções, o objetivo do presente estudo é demostrar se a prescrição será ou não interrompida nos casos de desclassificação perante o Tribunal do Júri.

\section{PRESCRIÇÃO PENAL}

O Estado possui o poder-dever de punição (jus puniendi), sendo esta uma das suas principais atribuições dentro do direito penal brasileiro, de forma a aplicar a punição legalmente imposta, sempre que uma infração penal for praticada. Por conseguinte, a prescrição penal se conceitua como a perda do direito do Estado de punir, em face do decurso de lapso temporal previsto em lei.

Vale ressaltar, vários conceitos foram atribuídos pela doutrina ao instituto da prescrição penal, dentre eles, abordando-se o assunto, Damásio de Jesus ${ }^{1}$ (2012, p. 761):

A palavra 'prescrição', no sentido comum, significa preceito, ordem expressa; no sentido jurídico, significa perda de um direito em face de seu não exercício dentro de certo prazo. Prescrição penal, num conceito preliminar, é a extinção do direito de punir do Estado pelo decurso do tempo. Preferimos dizer que a prescrição penal é a perda da pretensão punitiva ou executória do Estado pelo decurso do tempo sem o seu exercício.

Ainda, segundos ensinamentos de Cleber Masson (2015, p. 995), "Prescrição é a perda da pretensão punitiva ou da pretensão executória em face da inércia do Estado durante determinado tempo legalmente previsto."

Acrescenta-se, o instituto da prescrição está previsto expressamente no artigo 107, IV, do Código Penal ${ }^{2}$, como uma das causas excludentes da punibilidade. Em outras palavras, é igualmente uma das causas pelas quais o Estado perde o direito de punir o infrator, sendo este isento de qualquer punição estatal.

Conclui-se, a prescrição penal é tida como um dos institutos mais antigos e complexos do Direito, causando, até os dias atuais, uma série de divergências doutrinárias e jurisprudenciais, a exemplo do tema em discussão, possuindo grande relevância jurídica.

\section{ESPÉCIES DE PRESCRIÇÃO}

Com efeito, existem duas espécies de prescrição em nosso ordenamento jurídico, quais sejam, a prescrição da pretensão punitiva (PPP - art. 109 do $C P^{3}$ ) e a prescrição da pretensão executória (PPE - art. 110 do $\mathrm{CP}^{4}$ ).

\footnotetext{
${ }^{1}$ Promotor de Justiça em São Paulo; Doutor e Mestre em Direito Penal pela PUC/SP; Professor de Direito Penal da Rede LFG; Palestrante e Conferencista em todo o Brasil.

${ }^{2}$ Art. 107 - Extingue-se a punibilidade: [...] IV - pela prescrição, decadência ou perempção;

${ }^{3}$ Art. 109- A prescrição, antes de transitar em julgado a sentença final, salvo o disposto no § 1ํo do art. 110 deste Código, regula-se pelo máximo da pena privativa de liberdade cominada ao crime, verificando-se: I - em vinte anos, se o máximo da pena é superior a doze; II - em dezesseis anos, se o máximo da pena é superior a oito anos e não excede a doze; III - em doze anos, se o máximo da pena é superior a quatro anos e não excede a Colloquium Socialis, Presidente Prudente, v. 01, n. Especial 2, Jul/Dez, 2017, p.425-431. DOI: 10.5747/cs.2017.v01.nesp2.s0171
} 
Especificamente falando, a primeira se divide em: a) prescrição da pretensão punitiva propriamente dita - a qual ocorre antes do trânsito em julgado da sentença penal condenatória, utilizando-se a pena em abstrato cominada para o crime; b) prescrição superveniente ou intercorrente - aqui a pena utilizada como parâmetro para a verificação da prescrição é a pena em concreto, ou seja, ocorre entre a data da sentença penal condenatória e o trânsito em julgado para a defesa, sempre que houver demora na intimação do réu ou no julgamento do recurso interposto pela defesa; e c) prescrição retroativa - esta ocorre também após a sentença penal condenatória ou acordão condenatório, transitados em julgado, passando-se o caso a ser analisado com a pena em concreto, isto é, retroage à data do recebimento da denúncia ou queixa (Lei n. 12.234/10). Diferentemente da segunda, que se dá após a sentença condenatória transitada em julgado, fazendo com que o Estado perca o direito de executar punição já imposta, igualmente pelo decurso de lapso temporal previsto na lei.

\section{CAUSAS INTERRUPTIVAS DA PRESCRIÇÃO}

As causas interruptivas da prescrição penal, estão previstas no art. $117^{5}$ do Código Penal, por meio das quais o lapso temporal previsto legalmente é zerado, ou seja, possuem o condão de fazer com que sua contagem seja iniciada novamente. De acordo com Junqueira (2008, p. 195), as causas interruptivas da prescrição, "São aquelas que zeram o prazo prescricional. Elas obstam o curso da prescrição e fazem com que o prazo seja reiniciado a partir do primeiro dia."

O inciso I estabelece que o lapso temporal será interrompido pelo recebimento da denúncia ou queixa, isto é, a partir do momento em que as peças processuais forem recebidas em juízo, o prazo prescricional será automaticamente interrompido, iniciando-se a contagem.

O inciso II expressa, como segunda causa de interrupção da prescrição, a sentença de pronúncia. Neste ponto, vale destacar, as possíveis decisões a serem proferidas na primeira fase do rito do Tribunal do Júri (judicium accusationis) são: a) impronúncia - quando não existirem provas suficientes da autoria e da materialidade do crime, extinguindo-se o feito sem julgamento de mérito; b) absolvição sumária - quando o juiz constata a inexistência material do fato, negativa de autoria ou causas excludentes do crime; c) desclassificação - quando o juiz entender que se trata de crime cuja competência não pertence ao Tribunal do Júri, caso em que remeterá o processo para o juízo competente; e d) pronúncia (art. 413 do $\mathrm{CPP}^{6}$ ) - comportando-se maior relevância dentro do trabalho em questão, esta será proferida quando houver provas da existência do crime e indícios suficientes de autoria, sendo a única decisão que levará o acusado ao julgamento perante o conselho de sentença.

De acordo com os ensinamentos de Leal (1998, p. 487),

Nos crimes dolosos contra a vida, o julgamento é de competência do Tribunal do Júri. Recebida a denúncia e terminada a fase de instrução, o juiz entendendo que existem provas suficientes da autoria e do crime, pronuncia o acusado e o remete para o julgamento pelo júri. Essa sentença

\footnotetext{
oito; IV - em oito anos, se o máximo da pena é superior a dois anos e não excede a quatro; $V$ - em quatro anos, se o máximo da pena é igual a um ano ou, sendo superior, não excede a dois; VI - em 3 (três) anos, se o máximo da pena é inferior a 1 (um) ano.

${ }^{4}$ Art. 110 - Art. 110 - A prescrição depois de transitar em julgado a sentença condenatória regula-se pela pena aplicada e verifica-se nos prazos fixados no artigo anterior, os quais se aumentam de um terço, se o condenado é reincidente.

${ }^{5}$ Art. 117 - O curso da prescrição interrompe-se: I - pelo recebimento da denúncia ou da queixa; II - pela pronúncia; III - pela decisão confirmatória da pronúncia; IV - pela publicação da sentença ou acórdão condenatórios recorríveis; V - pelo início ou continuação do cumprimento da pena; VI pela reincidência.

${ }^{6}$ Art. 413. “O juiz, fundamentadamente, pronunciará o acusado, se convencido da materialidade do fato e da existência de indícios suficientes de autoria ou de participação."

Colloquium Socialis, Presidente Prudente, v. 01, n. Especial 2, Jul/Dez, 2017, p.425-431. DOI: 10.5747/cs.2017.v01.nesp2.s0171
} 
de pronúncia é causa interruptiva da prescrição, anulando todo o prazo prescricional anterior.

Por fim, os demais incisos estabelecem, como causas interruptivas da prescrição, a decisão confirmatória da pronúncia, a publicação da sentença ou acórdão condenatório recorríveis, o início ou continuação do cumprimento da pena e a reincidência.

\section{PRONÚNCIA COMO CAUSA INTERRUPTIVA DA PRESCRIÇÃO E POSTERIOR DESCLASSIFICAÇÃO NO TRIBUNAL DO JÚRI}

Antes da explanação referente ao tema, necessário se faz destacar, a sentença de pronúncia é a única decisão que levará o acusado ao julgamento perante o conselho de sentença no Tribunal do Júri, nos termos do artigo 413 do Código de Processo Penal. No mais, conforme já destacado no tópico anterior, é sabido, a pronúncia é causa interruptiva da prescrição, ou seja, proferida tal decisão, automaticamente o prazo prescricional volta a contar do início. Neste sentido, ensina Cleber Masson (2015, p. 1.015): “A interrupção se efetiva com a publicação da sentença de pronúncia, que prescinde de publicação na imprensa oficial. É suficiente, para essa finalidade, a publicação da decisão em cartório."

Diante de tal afirmação, uma série de divergências surgiu na doutrina e na jurisprudência a respeito da subsistência da pronúncia como causa interruptiva da prescrição, nos casos em que o conselho de sentença decide pela desclassificação do crime. Desta forma, faz-se necessário apresentar uma breve síntese dos principais argumentos apresentados neste sentido.

Inicialmente, cumpre destacar, quando se tratar de desclassificação ocorrida na primeira fase do júri (judicium accusationis), proferida pelo juiz togado, só haverá interrupção nos casos em que o delito for desclassificado por outro de competência do Tribunal do Júri, não havendo que se falar em interrupção nos demais casos. Neste contexto, Prado (2002, p. 645) explica:

Se na fase de pronúncia o juiz desclassifica o crime para outro, também de competência do Tribunal do Júri, ocorre a interrupção do prazo prescricional; porém, de desclassifica para outro delito, da competência do juiz singular, tal decisão não importa em interrupção da prescrição.

Todavia, quando se tratar da desclassificação na segunda fase do rito (judicium causae) mormente, destaca-se, nesses casos a competência continua sendo do juiz presidente do Tribunal do Júri -, existe certa divergência na doutrina, haja vista alguns doutrinadores sustentarem que a ocorrência da desclassificação do crime pelo conselho de sentença não acarreta interrupção do prazo prescricional pela anterior sentença de pronúncia. Dentre eles, vale destacar, Junqueira (2008, p. 195):

[...] não deveria interromper, pois se houve equívoco na capitulação do fato, que não deveria ser objeto de pronúncia, e como tal erro não pode ser imputado ao indivíduo, não pode ser ele prejudicado com a majoração dos prazos prescricionais gerada pela interrupção.

Assim, de acordo com entendimento em tela, sendo este minoritário, ocorrendo-se a desclassificação do crime para outro, cuja competência não pertence ao Tribunal do Júri, os efeitos da pronúncia, no caso a interrupção, não devem prevalecer, haja vista ser prejudicial ao próprio réu, devendo ser imediatamente afastada.

Em sentido contrário entende o posicionamento majoritário, o qual vem sustentando que, uma vez pronunciado o réu, a decisão servirá como marco interruptivo da prescrição, ainda que posteriormente o conselho de sentença venha a desclassificar o delito. De acordo com Pedroso 
(2017, p. 735), "Se a desclassificação do crime doloso contra a vida não provém do juiz togado, mas é proclamada pelos jurados no Tribunal do Júri, a pronúncia anterior conserva a interrupção prescricional que produziu".

Ainda, no mesmo sentido,

Uma vez pronunciado, persiste a força interruptiva da prescrição, ainda que o Tribunal do Júri, no julgamento em plenário, desclassifique o crime para outro que não seja de sua competência. É o que se extraí da súmula 191 do Superior Tribunal de Justiça. (MASSON, 2015, p. 1.016)

Nesta linha de raciocínio, fora editada a súmula 191 do Superior Tribunal de Justiça, a qual dispõe: "A pronúncia é causa interruptiva da prescrição, ainda que o Tribunal do Júri venha a desclassificar o crime." Desta forma, segundo a súmula, se o réu for pronunciado e o Tribunal do Júri desclassificar a infração, ainda assim, aquela primeira pronúncia terá força para interromper o prazo prescricional.

Acrescenta-se, ainda, o entendimento do Supremo Tribunal Federal e do Superior Tribunal de Justiça está firmado no sentido da subsistência da interrupção, senão vejamos:

DIREITO PENAL. PRESCRIÇÃO. INTERRUPÇÃO PELA PRONÚNCIA. POSTERIOR DESCLASSIFICAÇÃO DO DELITO PELO JÚRI. 1. A sentença de pronúncia interrompe o curso do prazo prescricional, que volta a correr por inteiro a partir de sua publicação (art. 117, inciso I, § 2ㅇ). 2. Esse efeito interruptivo subsiste, mesmo que, posteriormente, o Tribunal do Júri venha a desclassificar o delito, pelo qual o réu foi pronunciado, para outro que, em princípio, não comportaria pronúncia. 3. Precedente do S.T.F.: RTJ 124/969. 4. "H.C." indeferido. ${ }^{7}$

CRIMINAL. RESP. PRESCRIÇÃO. INOCORRÊNCIA. SENTENÇA DE PRONÚNCIA. POSTERIOR DESCLASSIFICAÇÃO PELO JÚRI. SÚM. 191/STJ. EXCLUDENTE DE LEGÍTIMA DEFESA E TESE NEGATIVA DE AUTORIA. INCABÍVEL REEXAME PROBATÓRIO. SÚM. 07/STJ. RECURSO DESPROVIDO. I. A sentença de pronúncia é março interruptivo da prescrição, ainda que ocorrida posterior desclassificação do delito pelo Tribunal do Júri. Súm. no 191/STJ. II. É inviável, nesta especial instância, a apreciação de alegações que envolvem o reexame de matéria fático-probatória. Súm. no 07/STJ. III. Recurso conhecido e desprovido. ${ }^{8}$

Assim, tem-se em vista, de acordo com o entendimento majoritário na doutrina e na jurisprudência, para fins de interrupção da prescrição, é irrelevante o fato de o crime ser ou não desclassificado em plenário, bastando-se que o réu seja pronunciado, para que o lapso temporal seja interrompido.

\section{CONCLUSÃO}

Conclui-se, dentro do rito especial do Tribunal do Júri, a toda evidência, sempre será necessária a visualização do momento processual atual, para analisar se a desclassificação terá ou não o condão de interromper o prazo prescricional. Se a desclassificação se efetivar pelo juiz

\footnotetext{
7 STF - HC: 73774 MG, Relator: SYDNEY SANCHES, Data de Julgamento: 30/04/1996, PRIMEIRA TURMA, Data de Publicação: DJ 31-05-1996 PP18803 EMENT VOL-01830-02 PP-00250.

${ }^{8}$ STJ - REsp: 94057 PR 1996/0025056-1, Relator: Ministro GILSON DIPP, Data de Julgamento: 25/05/1999, T5 - QUINTA TURMA, Data de Publicação: DJ 21.06.1999 p. 180 .
} 
togado, isto é, na primeira fase do rito em questão, só haverá interrupção da prescrição se o delito continuar sendo de competência do Tribunal do Júri. Entretanto, se descolocar para a competência do juízo singular, não há que se falar em prescrição.

No mais, quando a desclassificação ocorrer em plenário, embora existam alguns doutrinadores adeptos ao entendimento minoritário de não interrupção da prescrição, uma vez que se trata de equívoco não provocado pelo réu, sendo injusto e prejudicial a aplicação da interrupção, não restam dúvidas de que, ainda que haja posterior desclassificação pelos jurados, haverá interrupção da prescrição, nos termos da súmula 191 do STJ, bastando que o réu seja anteriormente pronunciado, sendo este o marco inicial da interrupção. Portanto o entendimento majoritário é o da interrupção da prescrição nos casos de desclassificação em plenário.

Finalmente, ainda que os fundamentos utilizados pelo entendimento minoritário sejam viáveis, andou bem o Superior Tribunal de Justiça ao sumular o entendimento explicitando a subsistência da pronúncia nos casos de desclassificação, afinal, ao se analisar o art. 117, II, do Código Penal, é fácil constatar que o fato de ser proferida uma decisão de pronúncia, pelo juiz togado, basta para que o lapso temporal seja reiniciado, sendo irrelevante, para fins de prescrição, posterior desclassificação do delito em plenário.

\section{REFERÊNCIAS}

AVENA, Norberto. Processo penal esquematizado. 4. ed. Revista atualizada e ampliada. São Paulo: Editora Método, 2012.

BEM, Leonardo Schmitt de; MARTINELLI, João Paulo Orsini. Lições fundamentais de direito penal: parte geral. São Paulo: Saraiva, 2016.

BRASIL. Código de Processo Penal. Decreto-Lei no 3.689, de 3 de outubro de 1941. Vade Mecum. São Paulo: Saraiva, 2017.

BRASIL. Código Penal. Decreto-Lei no 2.848, de 7 de dezembro de 1940. Vade mecum. São Paulo: Saraiva, 2017.

BRASIL. Superior Tribunal de Justiça. Criminal. REsp. Prescrição. Inocorrência. Sentença de pronúncia. Posterior desclassificação pelo júri. Súm. 191/STJ. Excludente de legítima defesa e tese negativa de autoria. Incabível reexame probatório. Súm. 07/STJ. Recurso desprovido. REsp 94057 PR 1996/0025056-1. Partes: Relator Gilson Dipp. Brasília, 25 de maio de 1999. Disponível em: <https://stj.jusbrasil.com.br/jurisprudencia/8391890/recurso-especial-resp94057-pr-1996-0025056-1-stj>. Acesso em: 24 jul. 2017.

BRASIL. Superior Tribunal de Justiça. Penal. Júri. Pronúncia. Causa interruptiva da prescrição. Desclassificação. CP - Art. 117, II. REsp 48916-4 SP. Partes: Relator: Ministro Edson Vidigal, Recorrente: Ministério Público do Estado de São Paulo, Recorrido: Valter Carlos Correa, Advogado: Jamil Corvello. Brasília, 22 de março de 1995 . Disponível em: <https://ww2.stj.jus.br/processo/ita/documento/mediado/?num_registro=199400156685\&dt_p ublicacao=24-04-1995\&cod_tipo_documento=>. Acesso em: 25 jul. 2017.

BRASIL. Supremo Tribunal Federal. Prescrição. Interrupção pela pronúncia. Posterior desclassificação do delito pelo júri. HC 73774 MG. Partes: Relator Sidney Sanches, Walter Carlos Correia, Paulo Ferreira de Carvalho, Superior Tribunal de Justiça. Brasília, 30 de abril de 1996. 
Disponível em: <https://stf.jusbrasil.com.br/jurisprudencia/744131/habeas-corpus-hc-73774-mg>. Acesso em: 24 jul. 2017.

JESUS, Damásio de. Direito penal: parte geral. v. 1. 33. ed. São Paulo: Saraiva, 2012.

JUNQUEIRA, Gustavo Octaviano Diniz. Direito penal. 7. ed. São Paulo: Premier Máxima, 2008.

LEAL, João José. Direito penal geral. São Paulo: Atlas, 1998.

MASSON, Cleber. Código penal comentado. 4. ed. Revista atualizada e ampliada. Rio de Janeiro: Forense; São Paulo: Método, 2016.

MASSON, Cleber. Direito penal esquematizado: parte geral. v. 1. 9. ed. Revista atualizada e ampliada. Rio de Janeiro: Forense; São Paulo: Editora Método, 2015.

MOUGENOUT, Edilson Bonfim. Curso de processo penal. 8. ed. São Paulo, Saraiva, 2013.

PEDROSO, Fernando de Almeida. Direito penal: parte geral. 5. ed. Leme: J. H. Mizuno, 2017.

PRADO, Luiz Regis. Curso de direito penal brasileiro. 3. ed. São Paulo: Editora Revista dos Tribunais, 2002. 